\title{
A DEVELOPMENT METHODOLOGY FOR COPPER END TERMINATION PASTE - PART 1: ORIGIN OF GREEN DEFECTS*
}

\author{
UMESH KUMAR ${ }^{\dagger}$ \\ Ferro Electronic Materials, 1325 Aspen Way, Vista CA 92083, USA
}

(Received December 2001)

\begin{abstract}
Copper $(\mathrm{Cu})$ based pastes have emerged as the termination materials of choice for ceramic capacitors with base metal internal electrodes. To prevent oxidation of nickel $(\mathrm{Ni})$ internal electrode and the copper terminations, it is necessary to fire the terminations in a nitrogen atmosphere. This requirement places significant restrictions on raw material selection for the termination pastes. For example, acrylic-based resins are used as organic binder for their clean burning characteristics over the traditional ethyl cellulose based binder system. As the viscoelastic behavior of acrylic resin systems are different to those of cellulose systems, differences are observed in the flow behavior of the paste. In this paper, the influence of paste rheology on the green cosmetic defects such as mooning, peaking, etc. is discussed. Additionally, the influence of process condition such as dipping parameters, drying conditions etc., on the green cosmetic defects are discussed. Finally, properties of a copper termination, which can be processed between $800-825^{\circ} \mathrm{C}$, are discussed.
\end{abstract}

Keywords: capacitor termination, ceramic capacitors, Ni based electrodes, green defects

\section{INTRODUCTION}

To address the market driven cost reduction, major capacitor manufacturers have changed their capacitor manufacturing systems to utilize low cost Ni based electrodes. For this capacitor system, $\mathrm{Cu}$ based terminations are now accepted as industry standard. To develop copper termination paste, a systematic approach was used Ref. [1]. Paste development was divided into five phases. During the first phase, desired characteristics of raw materials were determined (Tab. I). In the second phase, desired particle size distribution of copper powder for optimum densification was determined. In phase 3, the green cosmetic defects were corrected. In phase 4, the fired cosmetic defects were corrected. In the final phase, the paste recipe was refined to address dimensional, cosmetic, electrical, mechanical and reliability requirements of the termination and the capacitors.

\footnotetext{
* An earlier version of this paper was published in the Proceedings of the 15th Annual European Passive Components Conference (CARTS-EUROPE 2001), 15-19 October 2001, pp. 197-205.

$\dagger$ Tel.: (760)305-1026; E-mail: kumaru@ferro.com
} 
TABLE I Raw Materials Selection Criteria.

\begin{tabular}{|c|c|c|c|}
\hline & Material & Basic & Additional \\
\hline 1 & Metal powder & $\begin{array}{l}\text { Particle size distribution, surface } \\
\text { area, tap density, crystallanity }\end{array}$ & $\begin{array}{l}\text { Oxygen content, carbon } \\
\text { content }\end{array}$ \\
\hline 2 & Metal Flake & $\begin{array}{l}\text { PSD, flake aspect ratio, surface } \\
\text { area, tap density }\end{array}$ & $\begin{array}{l}\text { Oxygen concentration, carbon } \\
\text { content }\end{array}$ \\
\hline 3 & Glass & $\begin{array}{l}\text { Ability to provide liquid phase } \\
\text { sintering to metal, reactivity to } \\
\text { capacitor body, glass transition } \\
\text { temperature, acid resistance, } \\
\text { leach resistance }\end{array}$ & Processability in $\mathrm{N}_{2}$ \\
\hline 4 & Binder & $\begin{array}{l}\text { Solubility, decomposition } \\
\text { temperature, tack }\end{array}$ & Complete burn-off in $\mathrm{N}_{2}$ \\
\hline 5 & Solvent & $\begin{array}{l}\text { Drying characteristics, solubility } \\
\text { of all organic components }\end{array}$ & Drying below $175^{\circ} \mathrm{C}$ \\
\hline 6 & $\begin{array}{l}\text { Other organic additives: } \\
\text { dispersant/thixatrope etc. }\end{array}$ & $\begin{array}{l}\text { Compatibility and effectiveness } \\
\text { in the system }\end{array}$ & $\begin{array}{l}\text { Complete burn-off in } \mathrm{N}_{2} \text { and } \\
\text { the burn-out characteristics }\end{array}$ \\
\hline
\end{tabular}

This paper elaborates the observations made during the third phase. Green defects were corrected either by changing the paste properties or by adjusting the process parameters. To eliminate some of the defects, it was necessary to adjust both parameters.

In the last section of this paper, the properties of the optimized termination paste are described.

\section{Green Cosmetic Defects and Corrections}

During Phase 2, several green cosmetic defects were observed (Tab. II). Through careful analysis, it was possible to correlate many of the green defects to paste rheology and to dipping variables. For additional investigation, four different pastes with widely different rheology were made. In these pastes, the inorganic and resin content were kept constant. The low shear viscosity was changed through the concentration of minor additives such as surfactants, dispersants, flow modifiers etc. The rheology of the test batches is reproduced in Figure 1.

To study the influence of dipping parameters, a custom made dipping unit was used. A photograph of the dipping assembly is reproduced in Figure 2. In this set-up, a servomotor controls the vertical (z-direction) movement of a Palamor 7-x11 chip carrier plate. Several

TABLE II Green Cosmetic Defects: Origin and Potential Remedy.

\begin{tabular}{lcc}
\hline Defect & \multicolumn{1}{c}{ Origin } & \multicolumn{1}{c}{ Potential remedy } \\
\hline Mooning & $\begin{array}{c}\text { Viscosity, rheology and/or } \\
\text { surface tension of the paste, } \\
\text { drying rate } \\
\text { Powder to flake ratio, improper } \\
\text { dispersant, nature of the binder } \\
\text { Dipping parameters, paste } \\
\text { rheology, paste viscosity, } \\
\text { drying profile } \\
\text { Pimple }\end{array}$ & $\begin{array}{c}\text { Adjust dispersant, thixatrope } \\
\text { concentration }\end{array}$ \\
$\begin{array}{c}\text { Paste rheology, paste viscosity, } \\
\text { amount and size of the flakes, } \\
\text { dipping parameters, elastic } \\
\text { of the crown } \\
\text { nature of the binder }\end{array}$ & $\begin{array}{c}\text { Adjust the listed parameters, } \\
\text { additives to avoid skinning }\end{array}$ \\
& $\begin{array}{c}\text { Adjust the flake concentration. } \\
\text { Adjust viscosity, rheology, } \\
\text { dipping conditions and/or add } \\
\text { organic additives to increase } \\
\text { the viscous nature of the paste }\end{array}$ \\
\hline
\end{tabular}




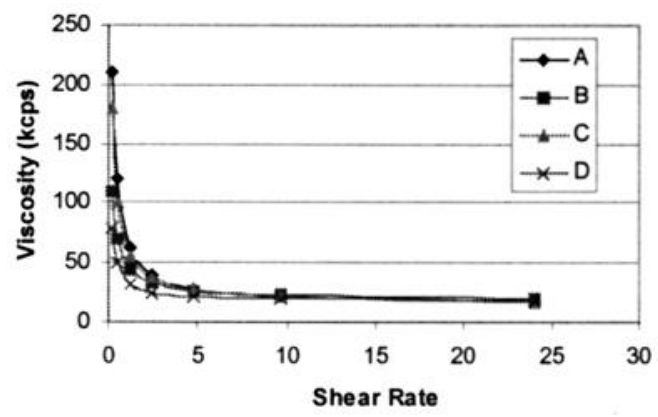

FIGURE 1 Rheology of test pastes.

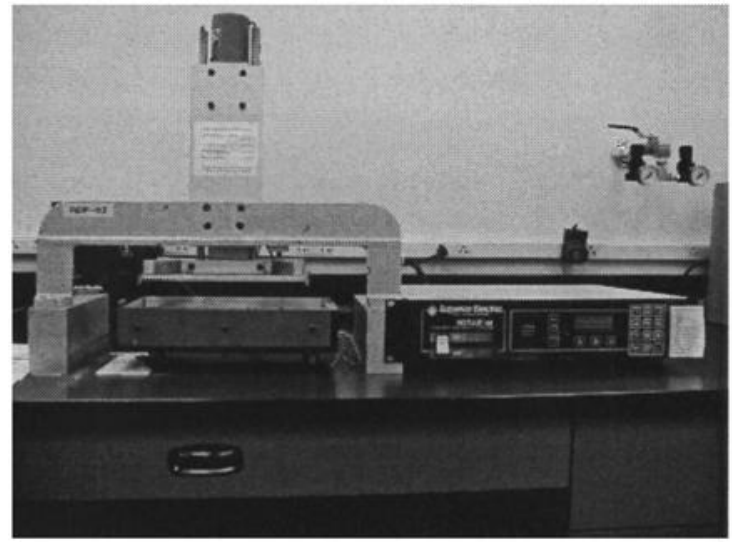

FIGURE 2 Termination unit.

dipping cycles, starting from the home position through pre-leveling, dipping, retraction, blotting and return to the home position are generated through a programmable motion control unit.

The three critical stages of termination application through dipping are insertion, dwell and withdrawal. Generally, capacitors arranged in a carrier plate are inserted into the paste at a predetermined insertion speed. After allowing the parts to dwell in the paste for a few seconds, they are withdrawn at a predetermined speed. For reproducible results, it is necessary to control the plate position and the motion, precisely. In this machine, the plate position can be controlled within 1 mil accuracy. The speed can be changed at $0.1 \mathrm{mil} / \mathrm{sec}$ interval.

After applying termination paste to the capacitors, they were dried in an IR belt oven. The process parameters such as peak temperature, heating profile, and soak time at the peak temperature were changed to understand the influence of drying conditions on defect formation.

\section{GREEN DEFECTS}

a. Uneven Termination Pick-up The photograph reproduced in Figure 3 was taken soon after dipping. These defects were mainly observed with paste A at severally over blot condition and at a withdrawal speed of $150 \mathrm{mil} / \mathrm{sec}$. When processed under same condition, uniform coating was observed with paste $\mathrm{D}$. 


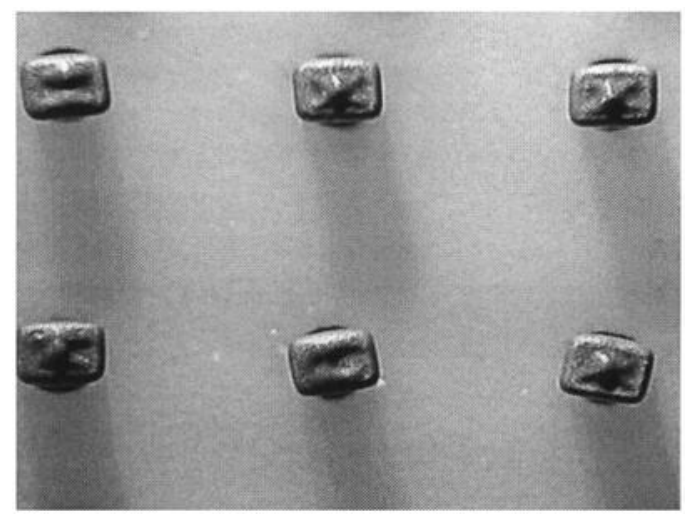

FIGURE 3 Uneven termination coating with paste (A). At over blot condition.

b. Pin Damage Pin damage occurred when the paste was not dried adequately. It was eliminated by increasing the peak temperature and by increasing the drying time.

c. Chipped Corners These defects were observed during phase 2. By analyzing the paste chemistry, a clear correlation was established between resin concentration and the defects. Additional tests proved that it was necessary to increase the green strength and to avoid over drying. These defects were eliminated by optimizing the resin content and by adjusting the drying conditions.

d. Mooning In some cases, severe mooning, as seen in Figure 5, was observed. It was possible to affect this defect by changing the rheology of the paste and by altering the drying rate. Among the two, the mooning was most affected by the rheology (Fig. 6).

e. Dimpling In some cases, a concave depression at the crown was observed (Fig. 7). Though several factors contributed to this defect, drying parameters showed the most influence.

f. Peaking In some cases, instead of concave depression a convex protrusion, namely peaking, was observed (Fig. 8). It was possible to minimize peaking by controlling flake size and the concentration. Further control was achieved through rheology modification.

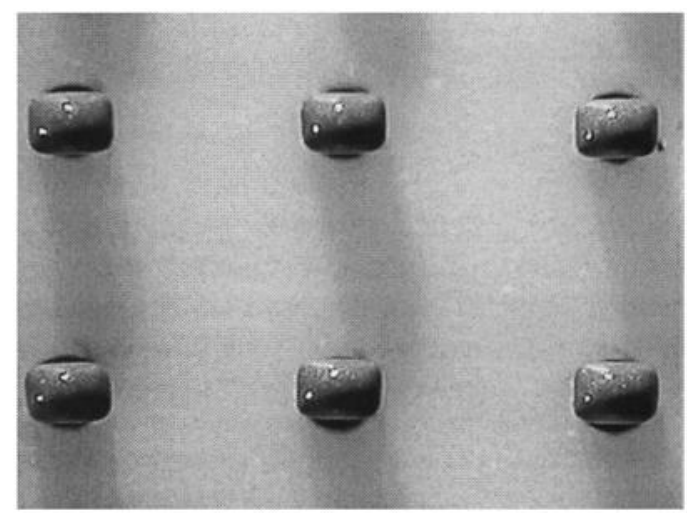

FIGURE 4 Uniform termination coverage with paste (D). 


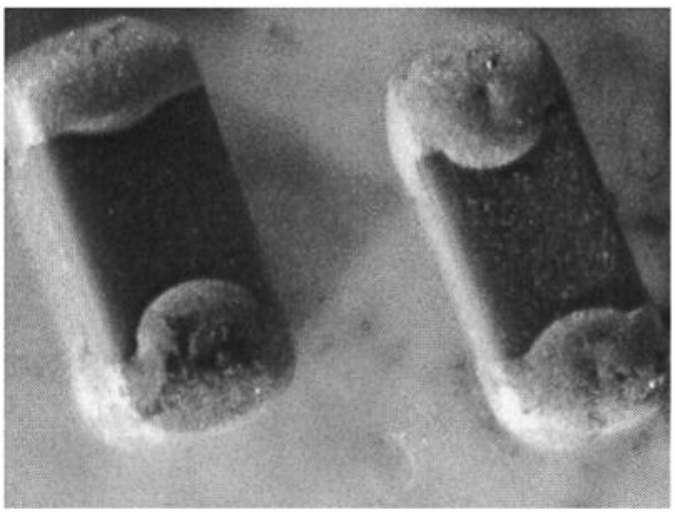

FIGURE 5 Green cosmetic defect: Mooning.

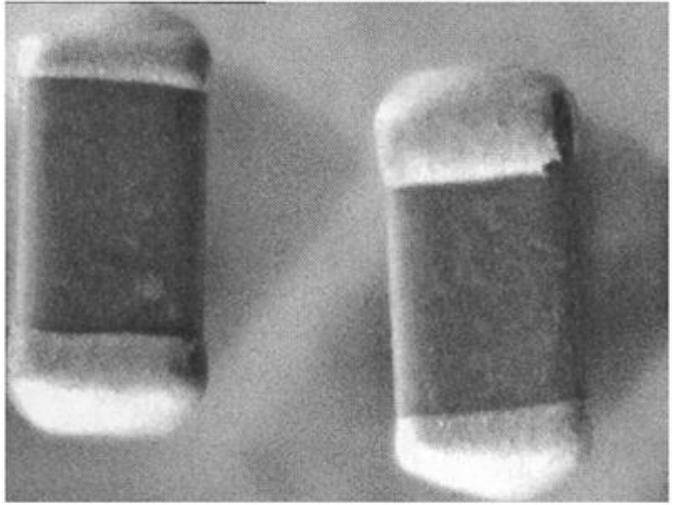

FIGURE 6 Green cosmetics: Side band after rheology adjustment.

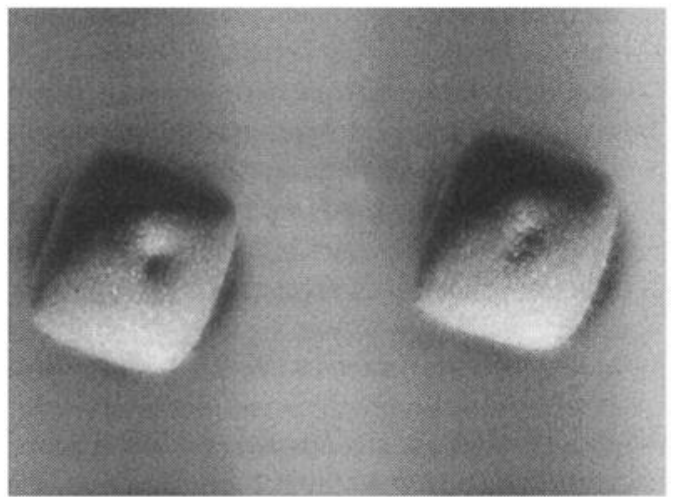

FIGURE 7 Green cosmetic defects: Dimpling. 


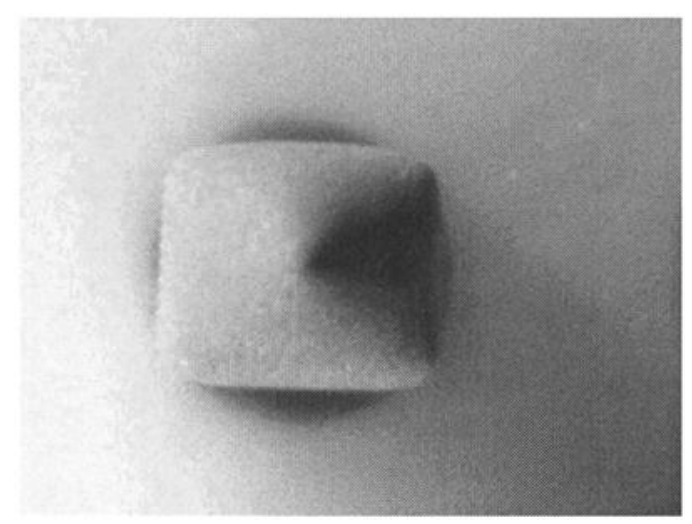

FIGURE 8 Green cosmetic defect: Peaking.

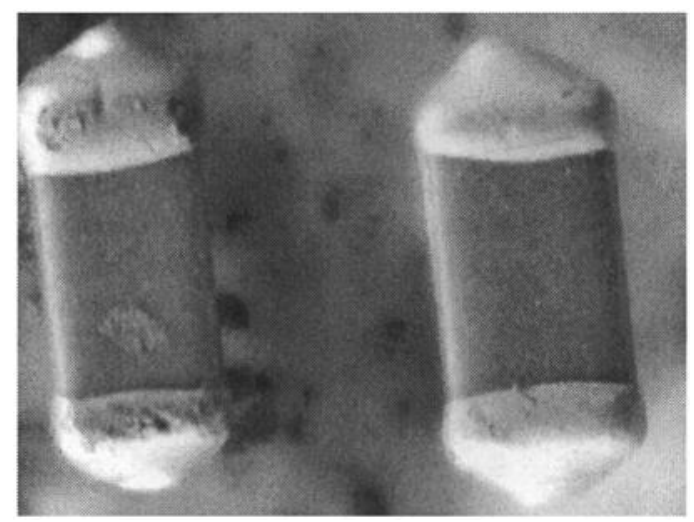

FIGURE 9 Green cosmetic defect: Mound.

g. Mound in the Middle of the Crown An extreme case of peaking is mound formation (Fig. 9). While applying copper paste, during the part removal stage a string was observed between the paste on the capacitor and the paste in the reservoir. After several experiments, it was determined that the withdrawal speed and the elastic nature of the paste controlled the string length. At separation, about half of the string fell back to the crown of the chip. Depending on the rheology and the flow behavior of the paste, either a peak or a mound was observed (Figs. 8 and 9). These defects were eliminated by adjusting the rheology and by introducing organic flow modifiers.

\section{h. Voids Voids were observed under three conditions.}

1. Rheology and dipping related: When paste A, having high thixotropic index, was used the classic voids were observed under certain conditions. The voids were observed at higher frequency with larger size parts and when the insertion and withdrawal rate of the parts were greater than $100 \mathrm{mil} / \mathrm{sec}$. (Fig. 10). In general the voids were smaller in size and 


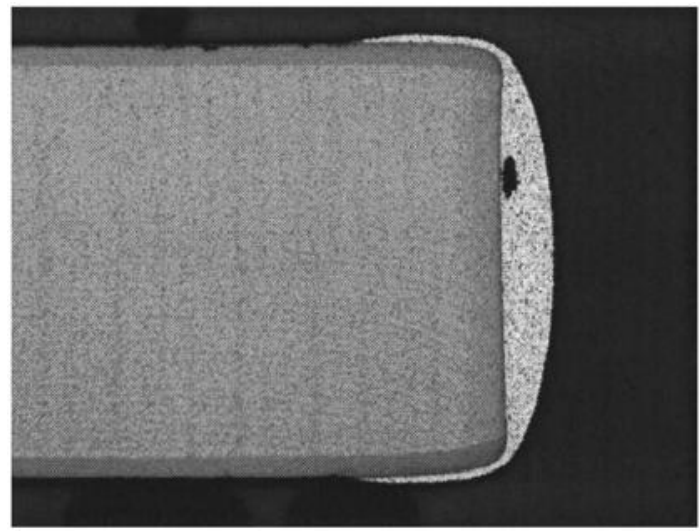

FIGURE 10 Voids: Rheology and dipping parameter related.

could be detected only by cross sectioning the fired parts. It was possible to eliminate the voids by reducing the thixotropic index and by reducing insertion and withdrawal speeds below $80 \mathrm{mil} / \mathrm{sec}$.

2. Blotting related: To control the crown thickness, blotting is commonly used. In some cases, fired cross section of the capacitors showed voids in the termination. To understand the void formation, the capacitors were blotted on a glass plate. The observations under different blotting conditions are reproduced in Figure 11 (Shown in next page). It was possible to eliminate the voids by changing paste rheology similar to that of paste $\mathrm{C}$ or $\mathrm{D}$, and by reducing blotting insertion and withdrawal speeds to $<50 \mathrm{mil} / \mathrm{sec}$.

3. Skinning related: Another kind of voids was observed while using certain solvents and at certain drying conditions (Fig. 12). These voids were closer to the surface and characteristically the dried surface of the crown showed wrinkles. In these parts, even after firing the wrinkled appearance remained.

It was possible to minimize this void by reducing the drying temperature to lower than $180^{\circ} \mathrm{C}$ and by adjusting the belt speed for gradual heating.

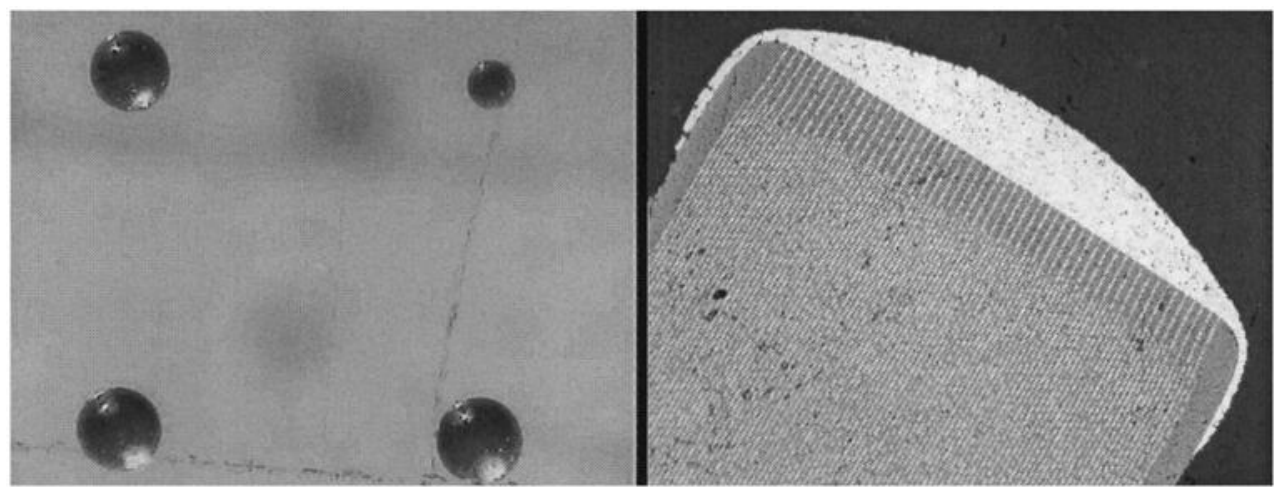

FIGURE 11a Minimum blot and the corresponding cross-section. 


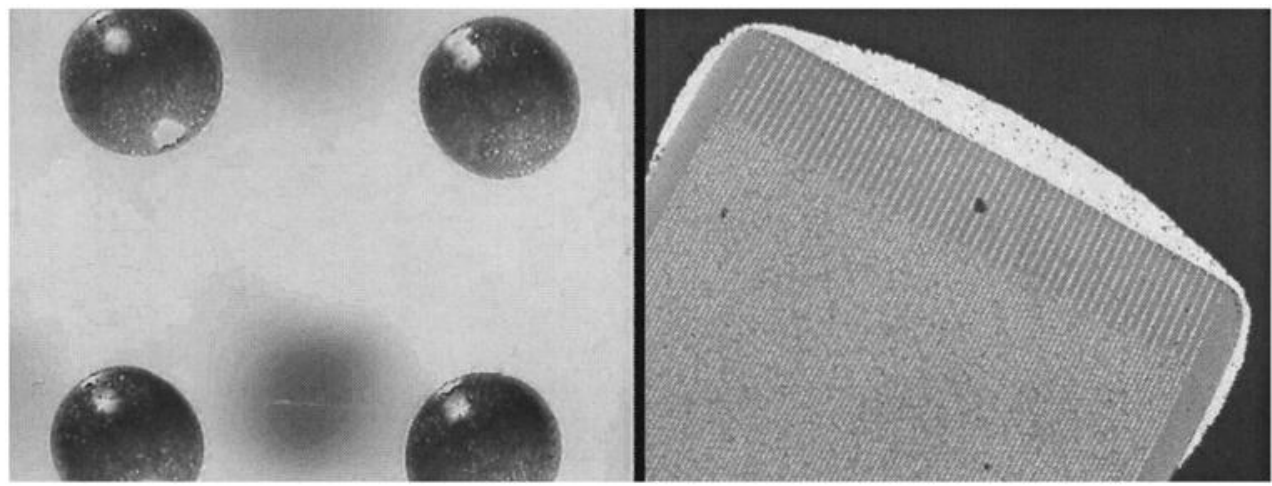

FIGURE 11b Proper blotting and corresponding cross-section.

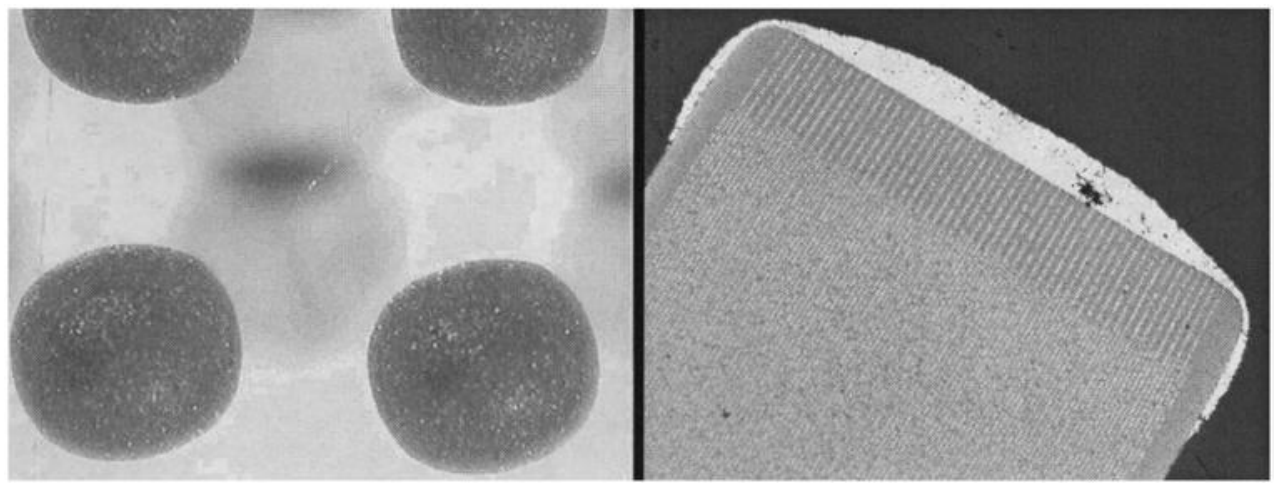

FIGURE 11c Over blotting and void formation.

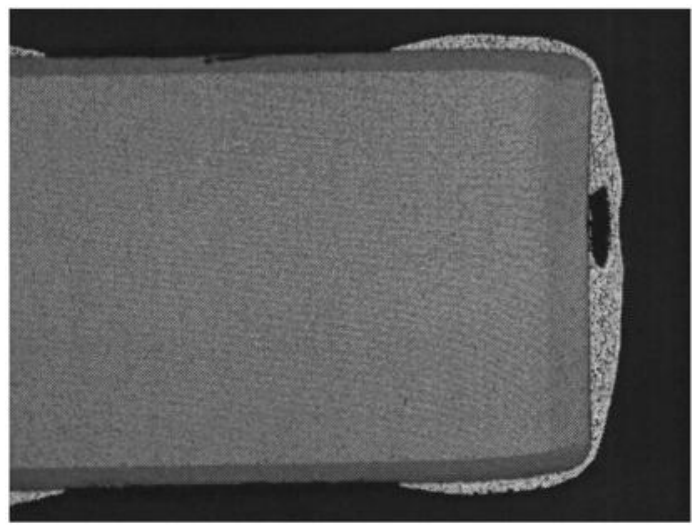

FIGURE 12 Voids: Skinning related. 


\section{TERMINATION PROPERTIES}

Identifying the root causes for the green defects allowed us to optimize the organic part of the paste recipe to eliminate the green defects. It was possible to identify a recipe to apply the paste within 30-sec. dip and blot cycle for optimum manufacturing through put.

Similar systematic study was conducted to refine the inorganic part of the paste recipe. A detailed description of the fired defects and the development methodology for the elimination will be presented elsewhere. In Table III, the type of post fire defects, potential origin and the potential remedies are listed.

In this section, some of the properties of the optimized termination are discussed. Optimum amounts of appropriate organic additives were utilized to achieve proper crown and side band cosmetics (Figs. 13-14).

Glass concentration and metal flake to sphere ratios were optimized to obtain derired density (Fig. 15), platability, adhesion strength and capacitor reliability.

In Table IV, the adhesion strength and the basic reliability properties are listed. The adhesion strength was measured by lead pull test method. During the pull strength measurement, the breakage occurred at the ceramic termination interface with a small chunk of ceramic, indicating very good adhesion.

TABLE III Post Firing Defects: Origin and Potential Remedy.

\begin{tabular}{|c|c|c|}
\hline Defect & Origin & Potential remedy \\
\hline Termination lift-off & $\begin{array}{l}\text { High termination density, poor } \\
\text { termination ceramic bond }\end{array}$ & $\begin{array}{l}\text { Change glass concentration } \\
\text { Change flake/sphere ratio, } \\
\text { change glass }\end{array}$ \\
\hline Cracks under land & $\begin{array}{l}\text { Very strong bond between } \\
\text { termination and ceramic, } \\
\text { thermal expansion mismatch }\end{array}$ & $\begin{array}{l}\text { Glass concentration, glass } \\
\text { chemistry, firing temperature }\end{array}$ \\
\hline Porous termination & $\begin{array}{l}\text { Metal sphere to flake ratio, } \\
\text { firing temperature and profile, } \\
\text { glass chemistry and concentration }\end{array}$ & Change one or more variable \\
\hline Dull appearance & Inadequate binder removal & $\begin{array}{l}\text { Adjust firing profile, furnace } \\
\text { ventilation, } \mathrm{N}_{2} \text { flow, change binder }\end{array}$ \\
\hline Glassy appearance & $\begin{array}{l}\text { Overfire, excessive glass in } \\
\text { the formulation }\end{array}$ & $\begin{array}{l}\text { Adjust firing temperature and } \\
\text { profile, adjust glass concentration }\end{array}$ \\
\hline
\end{tabular}

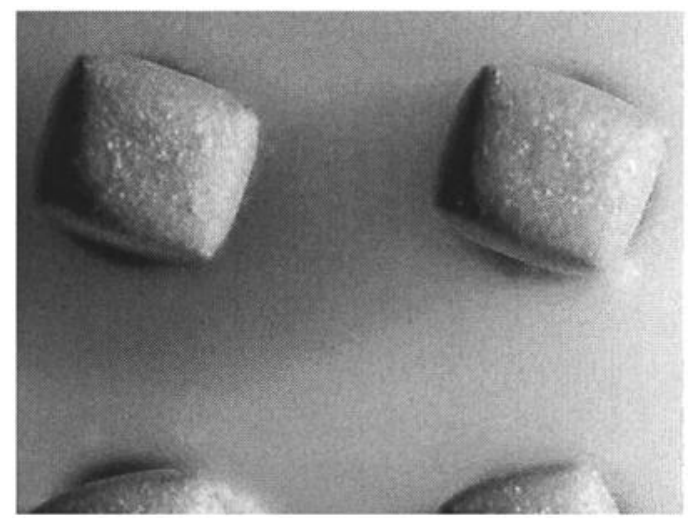

FIGURE 13 Properties of optimized termination paste: Typical crown cosmetics. 


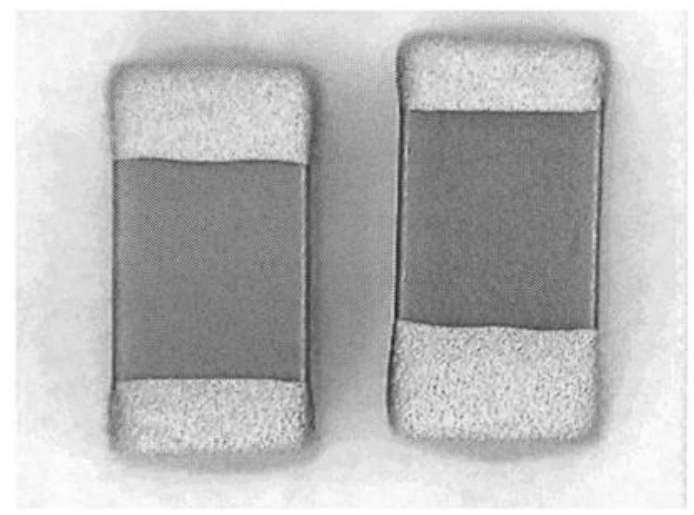

FIGURE 14 Properties of optimized termination paste: Side band cosmetics.

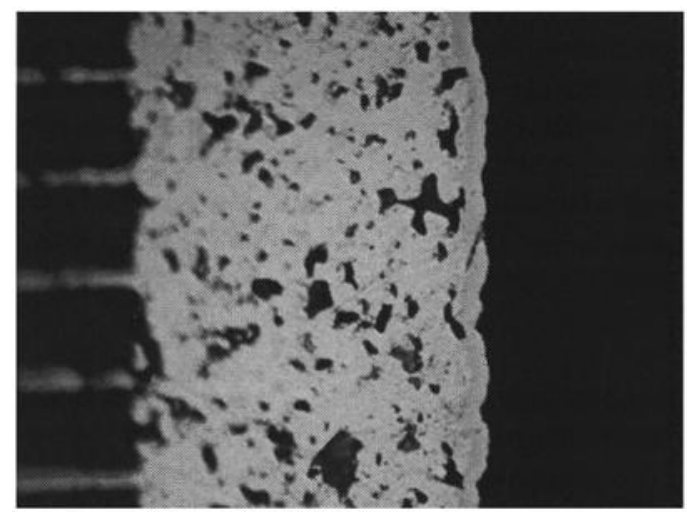

FIGURE 15 Properties of optimized termination paste: Typical fired cross section.

TABLE IV Typical Characteristics of the Cu Termination.

\begin{tabular}{ll}
\hline Paste Characteristics: & \\
Solid content & $75-85 \mathrm{wt} \%$ \\
Glass content & $3-8 \mathrm{wt} \%$ \\
Organic concentration & $\begin{array}{l}\text { Balance } \\
\text { Acrylic }\end{array}$ \\
Binder & \\
Firing Requirements: & $\mathrm{N}_{2}$ with $1-10 \mathrm{ppm} \mathrm{O}_{2}$ \\
$\quad$ Firing atmosphere & $800-825$ \\
$\quad$ Peak firing temperature $\left({ }^{\circ} \mathrm{C}\right)$ & \\
Physical Properties of Fired Termination: & $>7 \mathrm{lbs}$. \\
$\quad \begin{array}{l}\text { Pull Strength on } 1206 \text { X7R capacitors } \\
\text { Breakage mode }\end{array}$ & \\
Basic Reliability Related to Termination: & $0 / 1500$ \\
Thermal shock test with $60 / 40$ solder $@ 230{ }^{\circ} \mathrm{C}$ & \\
\hline
\end{tabular}




\section{SUMMARY AND CONCLUSIONS}

A systematic approach was used to develop a copper termination formulation for BME based multilayer ceramic capacitors. It was possible to eliminate green and fired cosmetic defects by understanding the origin and correlating them to the paste chemistry, rheology and the processing conditions. Appropriate paste chemistry and the firing profiles were used to achieve the optimum-fired properties.

\section{Acknowledgement}

The author acknowledges Ferro Electric Materials Division management for the support and encouragement and Gina Webb, Adam Smith and Rob Enering for their excellent technical assistance.

\section{Reference}

[1] Kumar, U. (2001). Copper end termination development methodology for BME based capacitors. Proceedings of the 21st Capacitors and Resistor Technology Conference, pp. 325-331. 

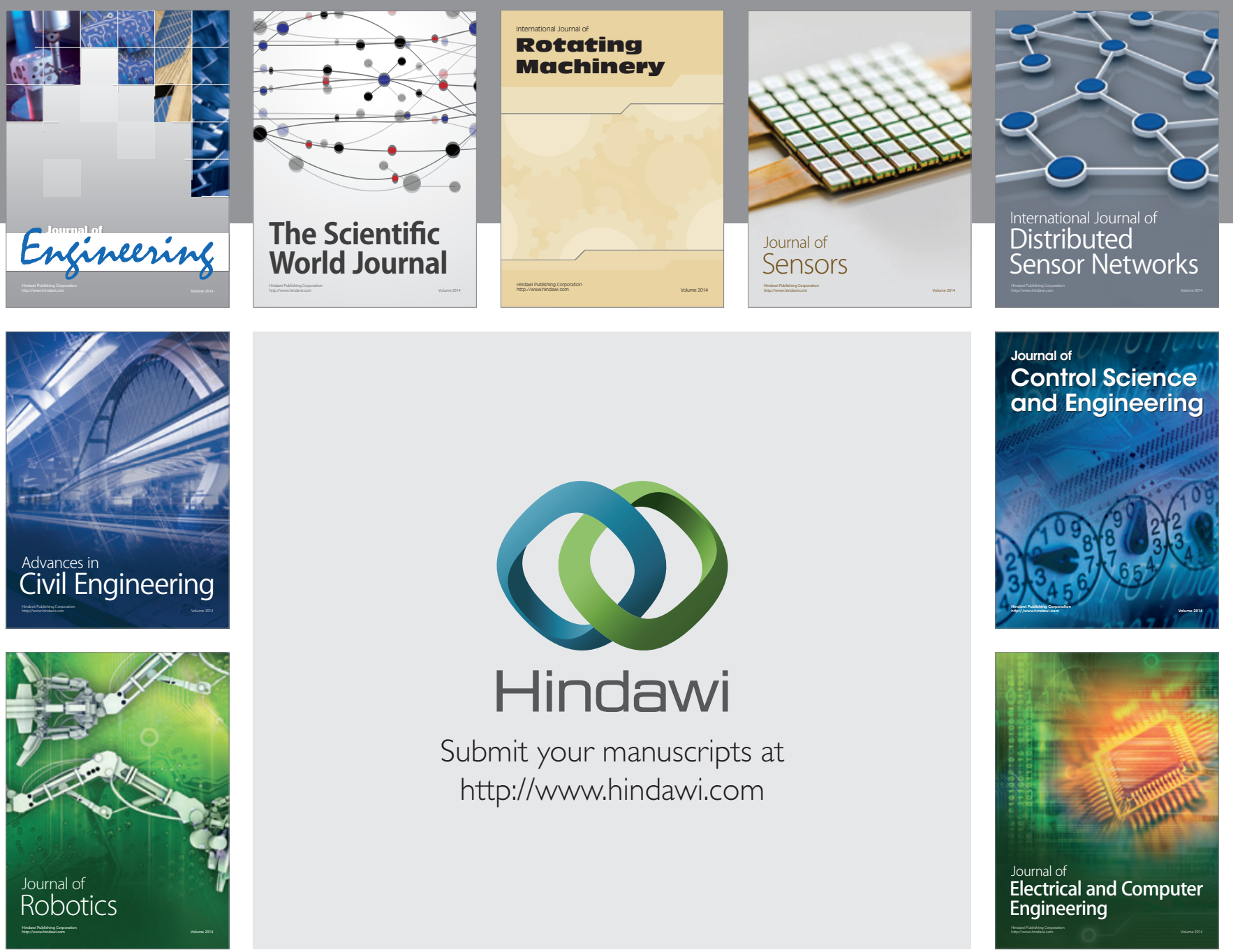

Submit your manuscripts at

http://www.hindawi.com
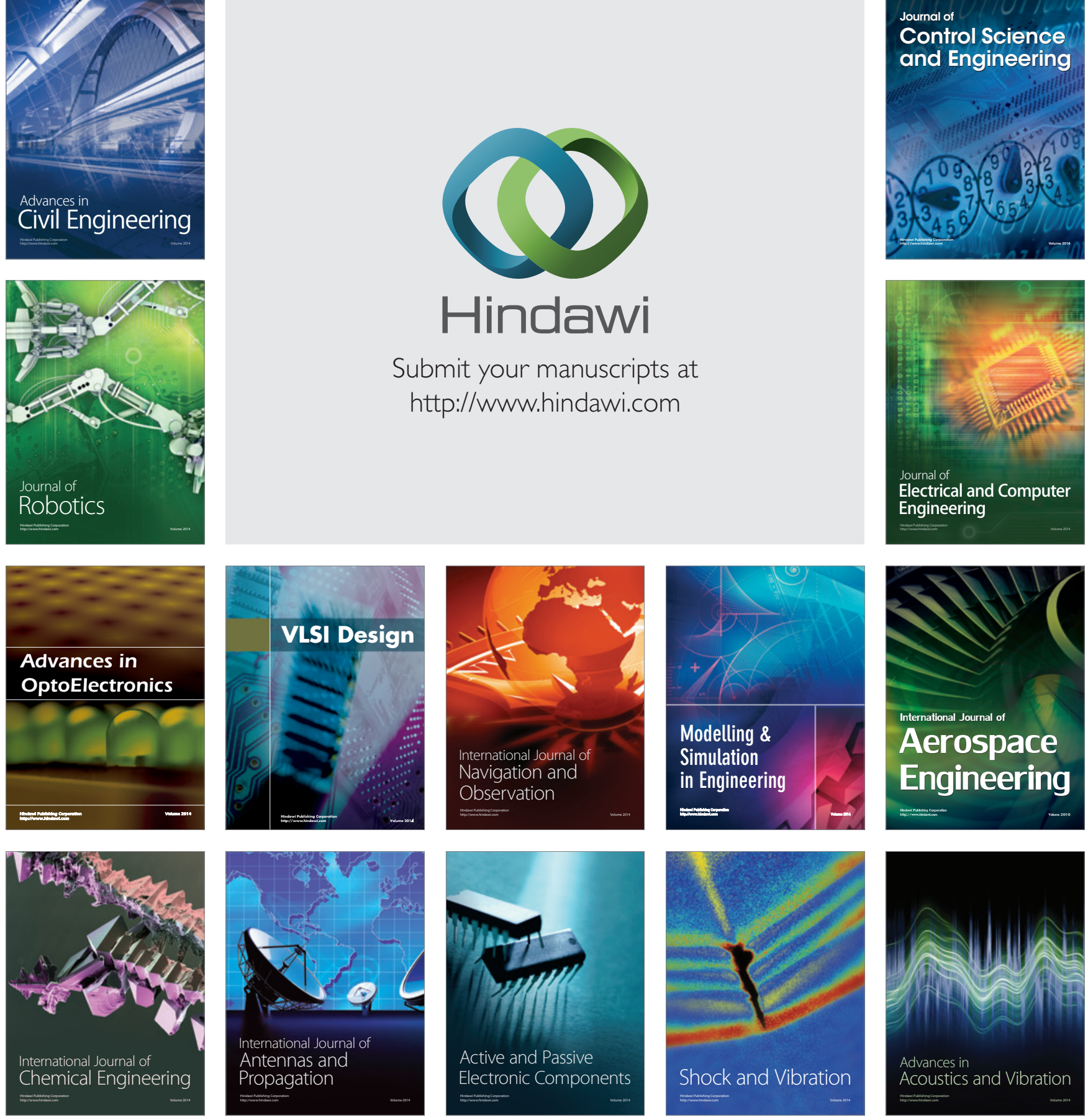